\title{
Insulin Promotes Corneal Nerve Repair and Wound Healing in Type 1 Diabetic Mice by Enhancing Wnt/ $\beta$-Catenin Signaling
}

Shuo Yang, ${ }^{* \dagger}$ Yangyang Zhang, ${ }^{*}$ Zhaohua Zhang, ${ }^{*}$ Jing Dan, ${ }^{*}$ Qingjun Zhou, ${ }^{*}$ Xiaochuan Wang, ${ }^{*}$ Weina Li, ${ }^{*}$ Li Zhou, * Lingling Yang, ${ }^{*}$ and Lixin Xie*

\begin{abstract}
From the State Key Laboratory Cultivation Base,* Shandong Provincial Key Laboratory of Ophthalmology, Shandong Eye Institute, Shandong First Medical University and Shandong Academy of Medical Sciences, Qingdao; the Eye Center, ${ }^{\dagger}$ Second Affiliated Hospital, School of Medicine, Zhejiang University, Hangzhou; and the Department of Ophthalmology, ${ }^{\ddagger}$ Tongji Hospital, Tongji Medical College, Huazhong, University of Science and Technology, Wuhan, China
\end{abstract}

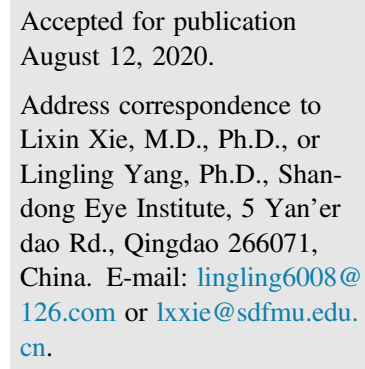

\begin{abstract}
The insulin and Wnt signaling pathways are involved in cell proliferation, tissue homeostasis, and tumorigenesis. However, their interrelationship in the pathophysiological process of diabetic corneal injury remains unclear. In this study, the role of insulin in the diabetic cornea was investigated in vitro, using cultured TKE2 cells and trigeminal ganglion neurons, and in vivo, by assessing corneal woundhealing responses in diabetic mice. A selective Wnt antagonist (XAV-939) and activator (BML-284) were used to regulate the interactions between insulin and the Wnt pathway. The results demonstrated that insulin promoted corneal epithelial wound healing and sensation recovery, whereas the expression of molecules involved in the Wnt/ $\beta$-catenin pathway was also up-regulated in the injured corneal epithelium. However, XAV-939 limited the insulin-induced epithelial and corneal nerve repair. By contrast, BML-284 treatment promoted the healing of the corneal epithelium and corneal nerve repair in diabetic mice. These results indicate that insulin, via Wnt signaling, contributes to diabetic corneal epithelial wound healing and nerve injury recovery and is, therefore, a potential protective factor for diabetic corneal epithelial wounds and nerve injury. (Am J Pathol 2020, 190: 2237-2250; https:// doi.org/10.1016/j.ajpath.2020.08.006)
\end{abstract}

Diabetes mellitus is a global chronic disease that causes ocular complications, which are gaining increasing attention. Primary diabetic eye diseases include diabetic retinopathy and diabetic keratopathy. Approximately $46 \%$ to $64 \%$ of patients with diabetes are affected by diabetic corneal nerve degeneration and delayed wound healing, which seriously affect their quality of life. ${ }^{1-3}$ Moreover, ocular surgery, which includes corneal transplantation, vitrectomy, and cataract surgery, is a risk factor for corneal epithelial injury in patients with diabetes. ${ }^{4-7}$ Therefore, diabetes-associated corneal damage has become one of the main causes of severe visual impairment in patients with diabetes. In previous studies on diabetic keratopathy, the roles and mechanisms of substance $\mathrm{P}$, vasoactive intestinal peptide, and small RNAs in diabetic keratopathy were discovered. $^{8-13}$ These findings enriched our understanding of diabetic keratopathy, but further exploration is required to gain complete insight into this complication.

The Wnt signaling pathway plays an essential role in tissue healing processes. ${ }^{14-20}$ In vitro experiments revealed that the activity of the $\mathrm{Wnt} / \beta$-catenin pathway was increased in the peripheral corneal epithelium, promoting its proliferation. $^{21,22}$ Ouyang et $\mathrm{al}^{23}$ demonstrated that the Wnt

Supported by the National Basic Research Program of China 2012 CB722409 (L.X.); the National Natural Science Foundation of China 81200665 (L.Y.), 81670828 (L.Y.), and 81900816 (S.Y.); the Natural Science Foundation of Zhejiang Province LQ19H120010 (S.Y.); the Innovation Project of Shandong Academy of Medical Sciences; the Academic promotion programme of Shandong First Medical University 2019ZL001 (L.X.); and the Taishan Scholar Youth Professional Program tsqn20161059 (Q.Z. and L.Y.).

Disclosures: None declared. 
pathway participated in corneal limbal stem cell differentiation, corneal wound healing, and corneal responses to mechanical injury. There has been increasing research into the role of the Wnt pathway in the development of diabetes and the effects of Wnt signaling in the eye. ${ }^{24-28}$ Activation of the Wnt pathway has a positive impact on the corneal limbal microenvironment, including limbal stem cells, and promotes corneal repair. ${ }^{23}$

Insulin is a biologically active polypeptide, critical for the maintenance and regulation of cell growth, proliferation, and metabolism. In the eye, insulin is found in the tear film. ${ }^{29-31}$ Insulin receptors (IRs) are found in the tissues of the eye surface and are abundant in the corneal epithelium. ${ }^{30-32}$ Although insulin is commonly used as a drug for the management of diabetes, more recently, it has been implicated in other aspects of research. Previous studies $^{33-35}$ have confirmed that the application of insulin eye drops could promote healing of the corneal epithelium in diabetic rats. Furthermore, a small clinical study in Malaysia found that topical application of insulin was beneficial for the ocular surface in patients with diabetes. ${ }^{36}$ However, elucidation of the therapeutic benefit and mechanism of action of topical insulin in diabetic keratopathy requires further study. The mechanism by which insulin promotes corneal epithelial healing, as well as its potential protective effect on corneal nerves, is yet to be elucidated.

In this study, we evaluated the protective effects of the local application of insulin on the corneas of type 1 diabetic mice and explored the mechanism of interaction between the insulin and Wnt signaling pathways in the healing process of the corneal epithelium and nerve injury recovery in diabetic mice.

\section{Materials and Methods}

Animals

Type 1 diabetes was induced in 6- to 8-week-old male C57BL/6J mice via i.p. injection of streptozotocin (SigmaAldrich, St. Louis, MO), as previously described. ${ }^{37}$ In the control group, a citric acid buffer solution was intraperitoneally injected into age-matched C57BL/6J mice. Follow-up tests showed that the blood glucose levels in diabetic mice were $\geq 16.7 \mathrm{mmol} / \mathrm{L}$ after 6 months. All animal experiments conformed to the Association for Research in Vision and Ophthalmology experimental animal ethical guidelines for ophthalmic use. Insulin eye drops were prepared from recombinant human neutral insulin $(100 \mathrm{IU} / \mathrm{mL}$; Lilly France S.A., Fegersheim, France) and normal saline at a final insulin concentration of $1 \mathrm{IU} / \mathrm{mL} .{ }^{33}$ The insulin eye drops $(3 \mu \mathrm{L})$ were freshly prepared on the day of use and applied four times per day for 1 week before and 1 week following epithelial scraping.

The Wnt inhibitor XAV-939 $(5 \mu \mathrm{L}, 0.6 \mu \mathrm{g} /$ eye; MedChemExpress, Monmouth Junction, NJ) or the Wnt activator BML-284 (5 $\mu \mathrm{L}, 0.5 \mu \mathrm{g} / \mathrm{eye}$; MedChemExpress) was
Table 1 Primary Antibodies for IF Staining and WB Analysis

\begin{tabular}{|c|c|c|c|}
\hline $\begin{array}{l}\text { Primary } \\
\text { antibody }\end{array}$ & Manufacturer & $\begin{array}{l}\text { Catalog } \\
\text { number }\end{array}$ & $\begin{array}{l}\text { Dilution } \\
\text { factor }\end{array}$ \\
\hline p-IRS1 (Y612) & $\begin{array}{l}\text { Abcam } \\
\quad \text { (Cambridge, MA) }\end{array}$ & Ab66153 & WB: 1000 \\
\hline p-IRS1 (S307) & $\begin{array}{l}\text { Beyotime } \\
\text { Biotechnology }\end{array}$ & 2AI623 & WB: 1000 \\
\hline IRS1 & Genetex (Irvine, CA) & GTX101284 & WB: 1000 \\
\hline GAPDH & $\begin{array}{l}\text { Goodhere (Hangzhou, } \\
\text { China) }\end{array}$ & $A B-P-R 001$ & WB: 1000 \\
\hline$\beta$-Actin & $\begin{array}{l}\text { Proteintech (Wuhan, } \\
\text { China) }\end{array}$ & 20536-1-AP & WB: 50,000 \\
\hline Histone3 & Proteintech & 17168-1-AP & WB: 3000 \\
\hline INSR & $\begin{array}{l}\text { Abgent } \\
\quad \text { (San Diego, CA) }\end{array}$ & AP7653a & WB: 4000 \\
\hline Cyclin D1 & CST (Danvers, MA) & 2978 & WB: 1000 \\
\hline Ki-67 & Abcam & Ab15580 & $\begin{array}{l}\text { WB: } 1000 \\
\text { IF: } 100\end{array}$ \\
\hline$\beta$-Catenin & Proteintech & 51067-2-AP & $\begin{array}{l}\text { WB: } 2000 \\
\text { IF: } 100\end{array}$ \\
\hline c-Myc & Abcam & Ab32072 & WB: 4000 \\
\hline TCF4 & Proteintech & 22337-1-AP & $\begin{array}{l}\text { WB: } 1000 \\
\text { IF: } 100\end{array}$ \\
\hline$\Delta \mathrm{Np} 63$ & $\begin{array}{l}\text { BioLegend } \\
\quad(\text { San Diego, CA) }\end{array}$ & 619002 & IF: 50 \\
\hline
\end{tabular}

GAPDH, glyceraldehyde-3-phosphate dehydrogenase; IF, immunofluorescence; INSR, insulin receptor; IRS1, insulin receptor substrate $1 ; \mathrm{p}$-IRS1, phosphorylated IRS1; TCF4, transcription factor 4; WB, Western blot.

injected into the conjunctiva beside the limbus 24 hours before corneal epithelial scraping. The mice in the control group were injected dimethyl sulfoxide, which was diluted in a buffer to the same concentration. The second subconjunctival injection was administered at the time of corneal epithelium removal.

\section{Corneal Sensitivity}

Corneal perception was determined using a Cochet-Bonnet esthesiometer (Luneau Technology, Chartres Cedex, France) in nonanesthetized, awake mice, with their eyelashes cut to reduce external influence. The initial filament length was 6 $\mathrm{cm}$, which was incrementally decreased by $0.5 \mathrm{~cm}$. The mouse blink response time at the longest length determined the central corneal sensitivity threshold. The measured fiber lengths were converted to actual pressure and compared using statistical test. Each mouse was tested four times, and the average value was used as the final result.

\section{Corneal Nerve Staining}

The mice were euthanized under excess anesthesia, and the eyes were removed and fixed in Zamboni fixative solution (Solarbio, Beijing, China) on ice for 1 hour. The intact corneal cup was cut along the limbus, and fixation was continued for an additional 30 minutes. The corneal cup was rinsed three times with Tris-buffered saline for 5 minutes 
Table 2 Primer Sequences for Real-Time Quantitative PCR

\begin{tabular}{llll}
\hline $\begin{array}{l}\text { Name } \\
\text { (mouse) }\end{array}$ & Primer & Sequence & $\begin{array}{l}\text { Size, } \\
\text { bp }\end{array}$ \\
\hline$\beta$-actin & $\begin{array}{l}\text { Forward } \\
\text { Reverse }\end{array}$ & $5^{\prime}$-AGCGAGCATCCCCCAAAGTT-3' & 285 \\
& $5^{\prime}$-GGGCACGAAGGCTCATCATT-3' & \\
$\beta$-catenin & Forward & $5^{\prime}$-AGACAGCTCGTTGTACTGCT-3' & 150 \\
& Reverse & $5^{\prime}$-GTGTCGTGATGGCGTAGAAC-3' & \\
TCF4 & Forward & $5^{\prime}$-CAGACACTCGCTCATGGTTG-3' & 163 \\
& Reverse & $5^{\prime}$-TGGTGGCATCCCTCTGTAAG-3' & \\
c-myc & Forward & $5^{\prime}$-CACTCACCAGCACAACTACG-3' & 196 \\
& Reverse & $5^{\prime}$-GTTCCTCCTCTGACGTTCCA-3' & \\
cyclinD1 & Forward & $5^{\prime}$-AGAAGTGCGAAGAGGAGGTC-3' & 157 \\
& Reverse & $5^{\prime}$-TTCTCGGCAGTCAAGGGAAT-3' & \\
\hline
\end{tabular}

TCF4, transcription factor 4 .

each and then incubated with an anti- $\beta$ III tubulin antibody (1:200; Sigma-Aldrich, Billerica, MA) for 24 hours in the dark. The samples were rinsed five times with Tris-buffered saline for 5 minutes each, then cut into petal shapes under a microscope, and imaged under a fluorescence microscope (Nikon, Shinagawa, Japan). Corneal innervation was quantified as a percentage of the tubulin $\beta$ III-positive area to the total area, as previously described. ${ }^{8,38}$ Whole corneal nerve densities were analyzed and calculated using the ImageJ software version 1.48 (NIH, Bethesda, MD; http://imagej. nih.gov/ij).

\section{Corneal Epithelial Wound Healing}

The mice were anesthetized via i.p. injection of chlorpromazine $(7 \mathrm{mg} / \mathrm{kg})$ and ketamine $(70 \mathrm{mg} / \mathrm{kg})$. An ophthalmic local anesthetic (oxybuprocaine hydrochloride eye drops) was used before the operation. The entire corneal epithelium, including the limbal region (marked with a 3-mm trephine), was scraped using an Algerbrush II corneal rust ring remover (Alger Equipment, Lago Vista, TX), and then the eye was treated with ofloxacin eye drops to prevent infection. Typically, one eye in each animal was wounded at a time. The defects in the corneal epithelium were visualized at 24, 48, and 72 hours after wounding by applying $0.25 \%$ fluorescein sodium and then imaging the epithelium under a slit lamp (BQ900; Haag-Streit, Bern, Switzerland). The stained area was analyzed using the ImageJ software, and the percentage of the residual epithelial defect area was calculated.

\section{Corneal Epithelial Progenitor Cell Culture and Treatment}

The mouse corneal epithelial cell line TKE2 ${ }^{39}$ was kindly provided by Dr. Tetsuya Kawakita of Keio University (Tokyo, Japan). After passaging, cells were plated in 6-well plates in a keratinocyte serum-free medium (Gibco Invitrogen, Carlsbad, CA) supplemented with $5 \mathrm{ng} / \mathrm{mL}$ human recombinant epithelial growth factor and $50 \mu \mathrm{g} / \mathrm{mL}$ bovine pituitary extract. The control group received mannitol (30 $\mathrm{mmol} / \mathrm{L}$ ), and the treatment groups received either only glucose $(30 \mathrm{mmol} / \mathrm{L})$ or glucose $(30 \mathrm{mmol} / \mathrm{L})$ and insulin $(0.1 \mathrm{IU} / \mathrm{mL})$. For the treatment with XAV-939 $(20 \mu \mathrm{mol} / \mathrm{L})$ or BML-284 $(0.001 \mu \mathrm{mol} / \mathrm{L})$, cells were cultured with the same glucose concentration in combination with insulin. After 3 days of incubation, the cell layers were wounded by scratching, and incubation was continued for 24 and 72 hours, followed by the determination of the levels of phosphorylated IR substrate 1 (IRS1), $\beta$-catenin, c-Myc, cyclin D1, transcription factor 4 (TCF4), and Ki-67.
A
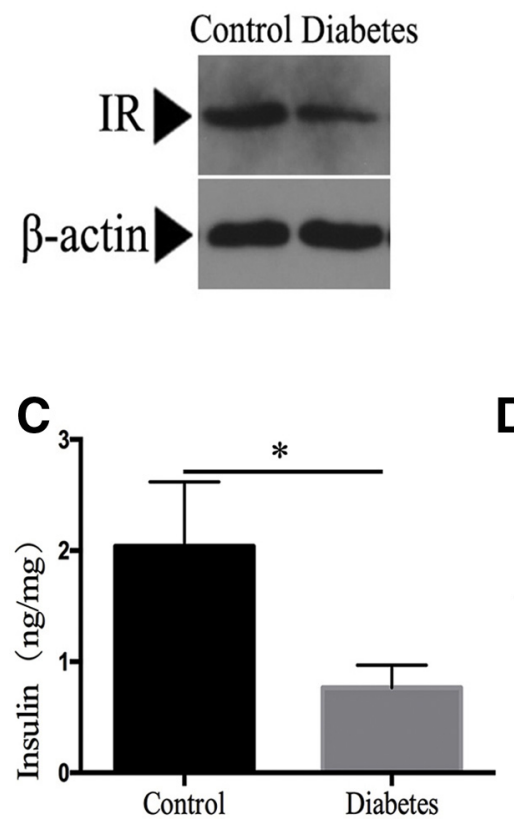

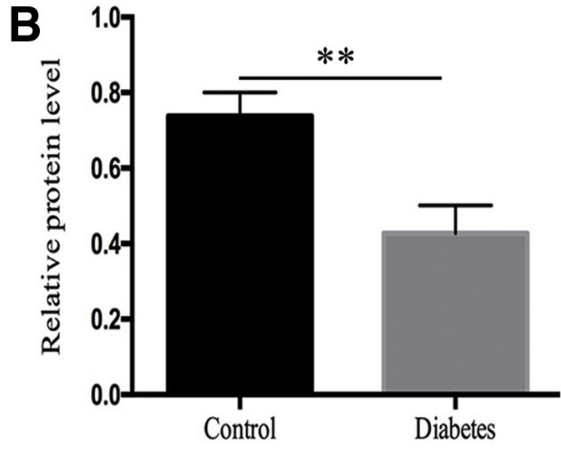

D

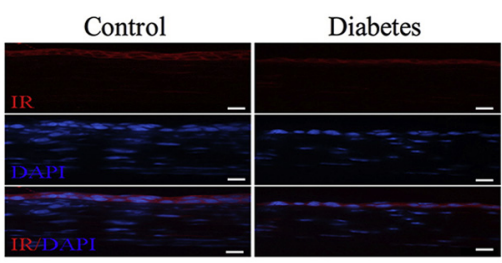

Figure 1 Insulin content and insulin receptor (IR) expression in corneal epithelium of diabetic and normal mice. A and B: Representative Western blot of IR expression in intact corneal epithelia of diabetic and normal mice. The results show that the expression of IR is significantly lower in the corneal epithelium of diabetic mice than in that of normal mice. C: Statistical analysis of the relative insulin content, measured using enzymelinked immunosorbent assay, in the corneal epithelium of diabetic and normal mice. The data show that insulin content is significantly lower in the corneal epithelium of the diabetic mice than in that of the normal mice. D: Immunofluorescence shows that the IR (red) is widely expressed in the cytomembrane of the corneal epithelium. $n=3(\mathbf{A}, \mathbf{B}$, and $\mathbf{D}) ; n=4(\mathbf{C}) .{ }^{*} P<0.05,{ }^{*} * P<0.01$. Scale bars $=50 \mu \mathrm{m}(\mathbf{D})$. 
A

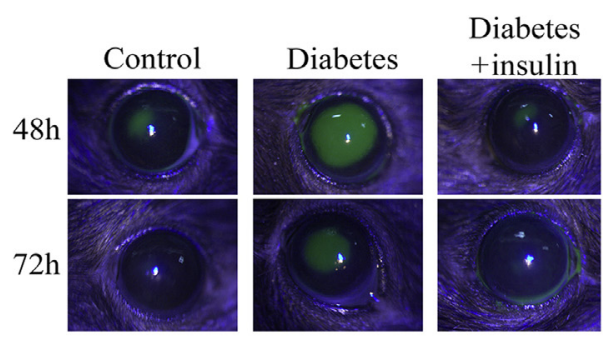

C

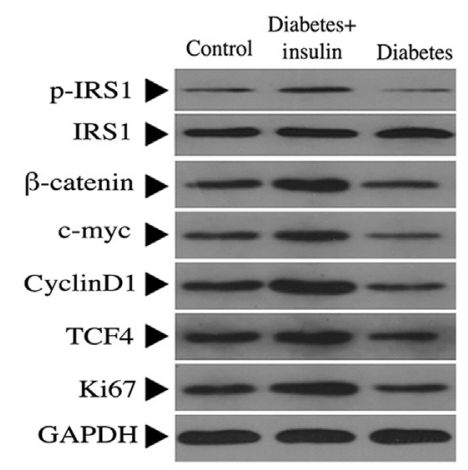

E
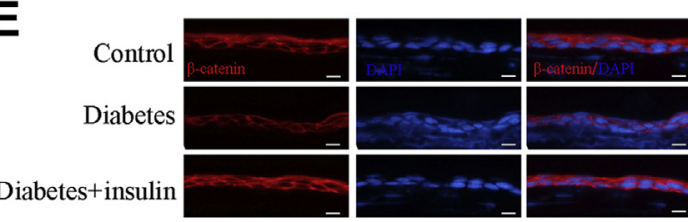

B

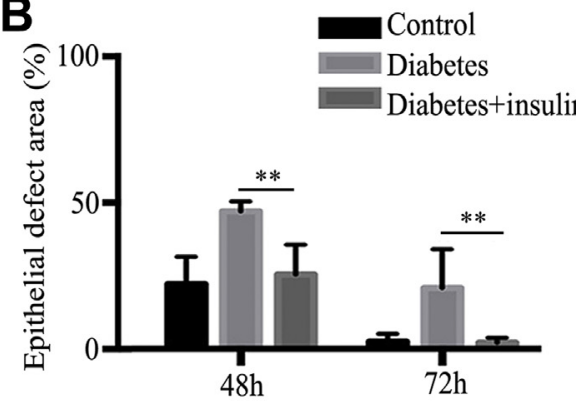

$\mathbf{D}$

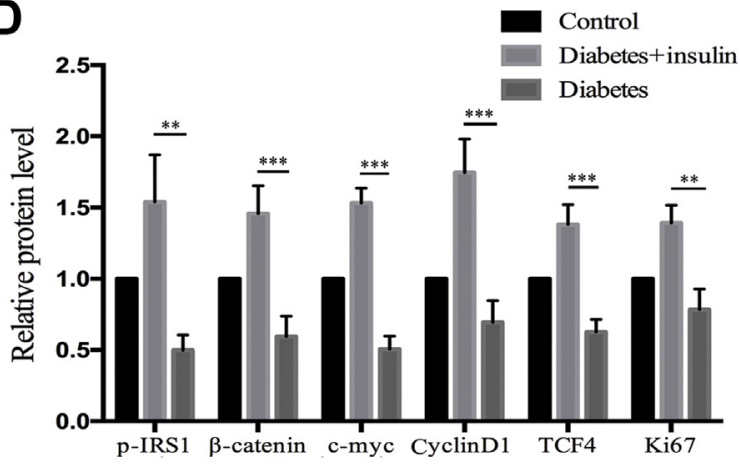

$\mathbf{F}$
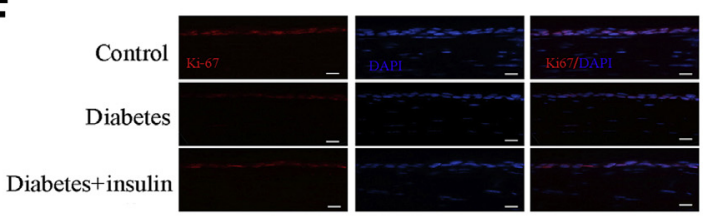

Figure 2 Insulin promotes corneal epithelial wound healing and enhances the Wnt/ $\beta$-catenin signaling pathway-related proteins in diabetic mice. Topical insulin application was used for 7 days to examine the rate of wound healing and reactivation of Wnt pathway-related proteins and Ki-67 in the corneal epithelium of diabetic mice. A: Fluorescein sodium staining was performed at the indicated time points after corneal epithelial scraping in mice. B: Statistical analysis of the defect area in the corneal epithelium at the indicated time points. C: Representative Western blots of proteins of interest in mouse corneal epithelia. D: Statistical analysis of the relative protein levels in the mouse corneal epithelia. $\mathbf{E}$ and $\mathbf{F}$ : Immunofluorescence staining for $\beta$-catenin and Ki-67 (red), respectively. Nuclei were labeled with DAPI (blue). $n=4$ (A and $\mathbf{B}) ; n=3(\mathbf{C}-\mathbf{F}) .{ }^{* *} P<0.01,{ }^{* * *} P<0.001$. Scale bars $=5 \mu \mathrm{m}$ (E and $\left.\mathbf{F}\right)$. GAPDH, glyceraldehyde-3-phosphate dehydrogenase; IRS1, insulin receptor substrate 1; p-IRS1, phosphorylated IRS1; TCF4, transcription factor 4.

\section{Enzyme-Linked Immunosorbent Assay}

The samples were prepared from $10 \%$ tissue homogenates. The supernatants were collected after centrifugation and were analyzed using an enzyme-linked immunosorbent assay kit for the detection of insulin (CEA448Mu; CloudClone Corp., Katy, TX), according to the manufacturer's instructions. The absorbance was read at $450 \mathrm{~nm}$ against a reference wavelength of $570 \mathrm{~nm}$ using a microplate reader (Molecular Devices, Sunnyvale, CA).

\section{Western Blot Analysis}

Western blotting was performed as previously described. ${ }^{37}$ Total protein was extracted from lysing mouse corneal epithelium samples and cultured TKE2 cells in radioimmunoprecipitation assay buffer. Protein quantification was performed using a kit (P0010; Beyotime Biotechnology, Beijing, China). Cytoplasmic and nuclear $\beta$-catenin was detected in TKE2 cells using the Minute cytoplasmic and nuclear fractionation kit (Invent, Beijing, China). The samples were separated using $8 \%$ to $12 \%$ SDS-PAGE and then transferred to a polyvinylidene fluoride membrane (Millipore, Billerica, MA). The blots were blocked in a $5 \%$ solution of dry nonfat milk for at least 1 hour and then incubated with primary antibodies (Table 1) in Tris-buffered saline plus Tween 20 for 1 hour at room temperature $\left(22^{\circ} \mathrm{C}\right)$. The blots were washed three times and then incubated with a horseradish peroxidase-conjugated secondary antibody (Amersham Biosciences, Piscataway, NJ). Finally, the blots were visualized via enzyme-linked chemiluminescence using an ECL kit (Chemicon, Temecula, CA).

\section{Immunofluorescence Staining}

The eyes were embedded in Tissue-Tek O.C.T. compound (Sakura Finetek, Tokyo, Japan), and sections (7 $\mu \mathrm{m}$ thick) were cut from frozen tissue. The sections were stained with primary antibodies at $4^{\circ} \mathrm{C}$ overnight, then washed and incubated with fluorescein-conjugated secondary antibodies (Table 1 ) at $37^{\circ} \mathrm{C}$ for 1 hour. TKE2 cells were plated in 48-well culture plates and allowed to adhere in the presence of appropriate drugs. Immunofluorescence staining was performed after 48 hours of culture, 

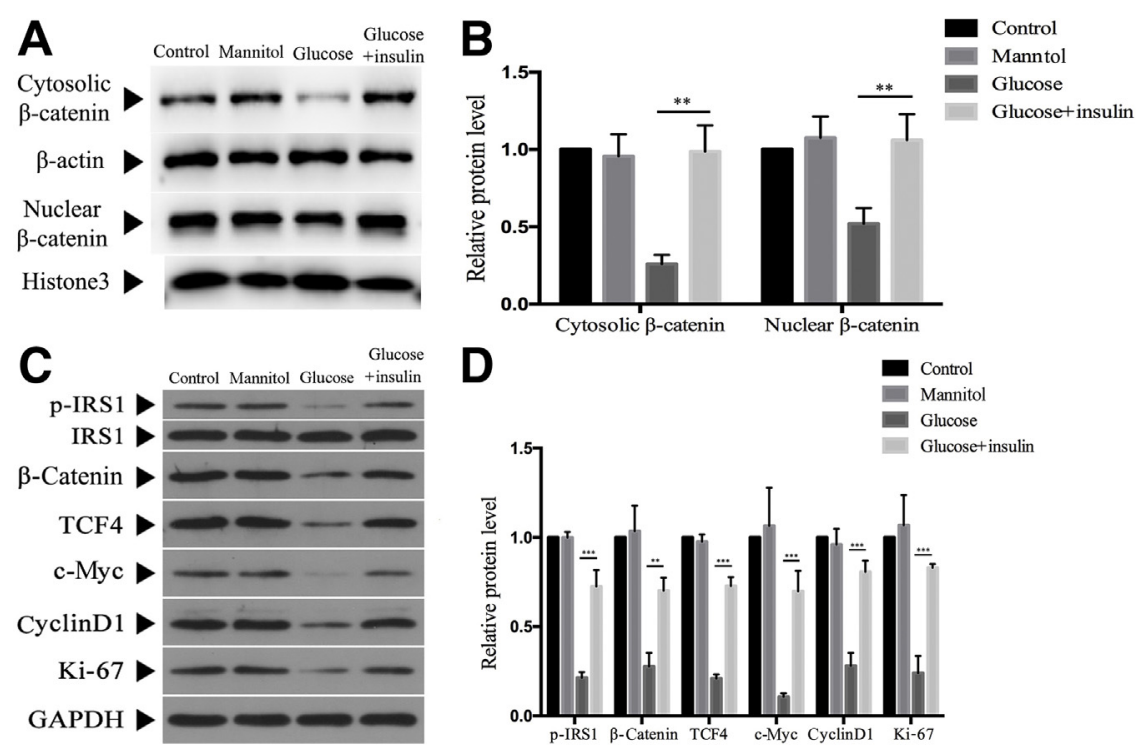

Figure 3 Insulin enhances the Wnt/ $\beta$-catenin signaling in TKE2 cells. A and B: Representative Western blots showing the levels of cytosolic and nuclear $\beta$-catenin in the control, mannitol, glucose, and glucose + insulin groups at 24 hours after injury in an in vitro scratch assay. The results show that the $\beta$-catenin levels significantly increase in the cytosol and nucleus in the insulin group. C: Representative Western blots showing the phosphorylated insulin receptor substrate 1 (p-IRS1), Wnt pathway-related proteins, and Ki-67 levels in the four groups. D: Statistical analysis of the relative protein levels show that insulin increases the p-IRS1 and Wnt pathway-related protein levels at 24 hours after injury in an in vitro scratch assay. E: Representative Western blots showing the p-IRS1, Wnt pathwayrelated proteins, and $\mathrm{Ki}-67$ levels in the four groups at 72 hours after injury in an in vitro scratch assay. F: Statistical analysis show that the relative levels of p-IRS1 and the Wnt pathway-related proteins are still increased in the insulin group. G: Immunofluorescence staining for $\mathrm{Ki}-67$ (green). Nuclei were labeled with DAPI (blue). $n=3(\mathbf{A}-\mathbf{G})$. ${ }^{*} P<0.05,{ }^{* *} P<0.01$, and ${ }^{* *} P<0.001$. Scale bars $=50 \mu \mathrm{m}(\mathbf{G})$. GAPDH, glyceraldehyde-3phosphate dehydrogenase; TCF4, transcription factor 4 .

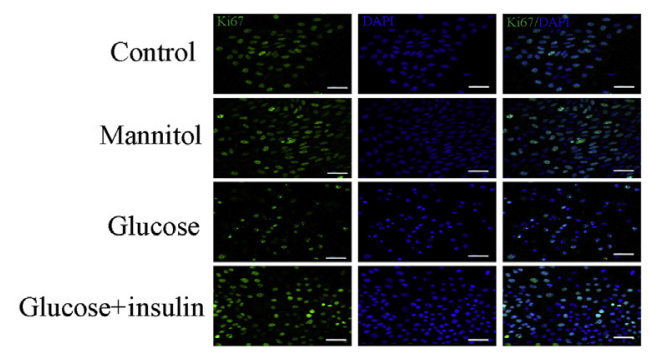

as described above. All stained samples were observed under a confocal microscope or an Eclipse TE2000-U microscope (Nikon) after counterstaining with DAPI.

\section{Trigeminal Ganglion Neuronal Cell Culture and Staining}

Primary trigeminal (TG) neuronal cells were cultured as described previously. ${ }^{8,40}$ Briefly, whole TG tissues were collected from mice and digested with papain and collagenase/ dispase. The isolated trigeminal ganglion cells were separated in Percoll gradients, then plated onto poly-D-lysine - and laminincoated slides (Thermo Fisher Scientific, Waltham, MA), and incubated in Neurobasal-A medium (Life Technologies, Grand Island, NY) with B27 supplement (Life Technologies). Cells were divided into the following five groups: control, mannitol, high glucose, high glucose + insulin + XAV-939, and high glucose + BML-284. The glucose, mannitol, insulin, XAV939, and BML-284 concentrations used were $30 \mathrm{mmol} / \mathrm{L}, 30$ $\mathrm{mmol} / \mathrm{L}, 0.1 \mathrm{IU} / \mathrm{L}, 20 \mu \mathrm{mol} / \mathrm{L}$, and $0.001 \mu \mathrm{mol} / \mathrm{L}$, respectively. After 24 hours of incubation, the ganglion cells were stained with an anti-ßIII-tubulin antibody (Sigma-Aldrich) for immunofluorescence analysis. Neurite outgrowth was analyzed and calculated using the quantitative nerve-tracing software (NeuronJ version 1.4.2; a plug-in of the ImageJ software).

\section{Real-Time Quantitative PCR}

Expression of the Wnt pathway-related genes was determined in TG cultures using real-time quantitative PCR. TG neuronal cells were rapidly collected, and total RNA was extracted using an RNA extraction kit (BD Biosciences, Palo Alto, CA). cDNA was generated using the RevertAid first-strand cDNA synthesis kit (Takara, Dalian, China), according to the manufacturer's instructions. Real-time quantitative PCR was performed using SYBR Green reagents and a 7500 real-time PCR system (Applied Biosystems, Foster City, CA). Relative mRNA expression levels were determined using to the $2^{-\Delta \Delta \mathrm{Ct}}$ method following the Minimum Information for Publication of Quantitative Real-Time PCR Experiments guidelines. The genespecific primer sequences and annealing temperatures are shown in Table 2. 
A
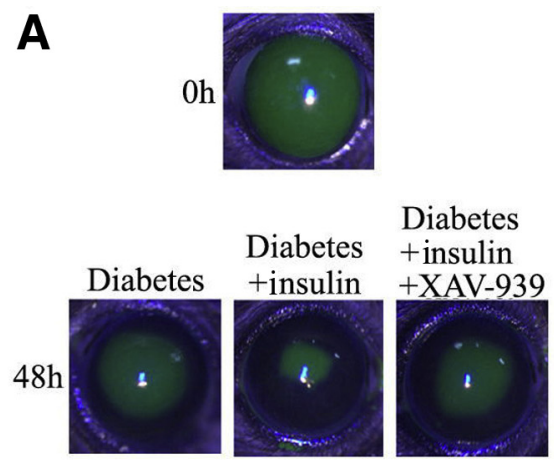

C

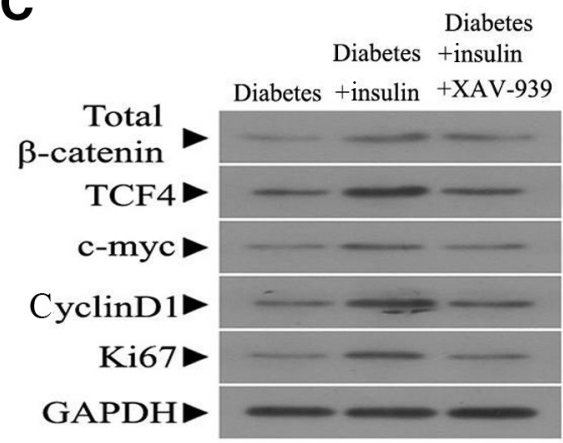

E
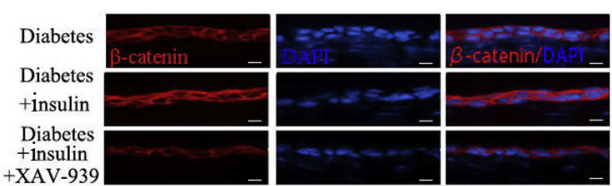

B

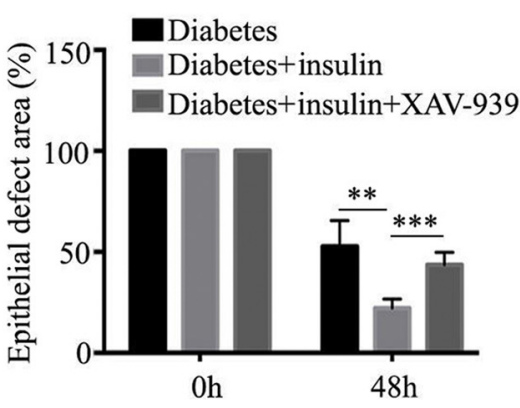

D

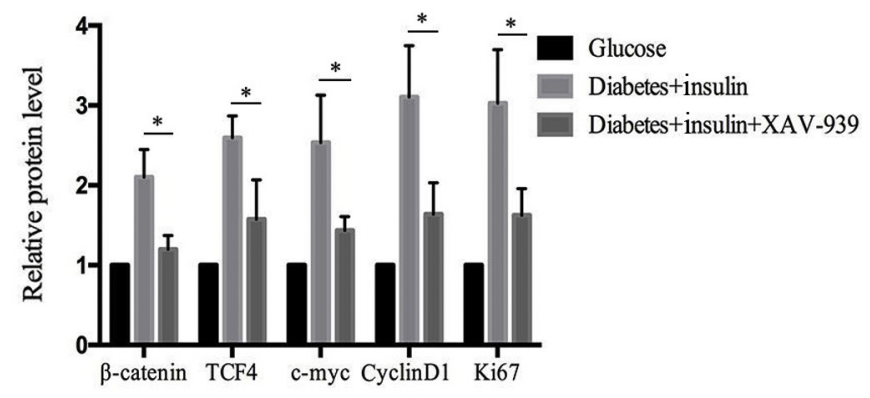

$\mathbf{F}$

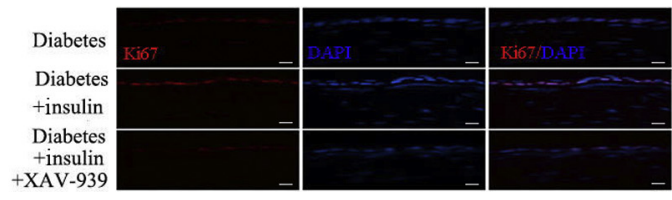

Figure 4 Wnt/ $\beta$-catenin signaling antagonist attenuates the effect of insulin on diabetic corneal epithelium repair. XAV-939 (Wnt/ $\beta$-catenin signaling antagonist) was administered via subconjunctival injection to mice. A: Fluorescein sodium staining at the indicated time points after corneal epithelial scraping in diabetes, diabetes + insulin, and diabetes + insulin + XAV-939 groups. B: Statistical analysis of the percentages of the defect areas at the indicated time points after corneal epithelium scraping. C: Representative Western blots showing the $\beta$-catenin, TCF4, c-Myc, cyclin D1, and Ki-67 levels in the corneal epithelium. D: Statistical analysis of the relative protein expression levels in the corneal epithelia. The results show that XAV-939 decreases the insulin-increased levels of the Wnt signaling pathway-related proteins. $\mathbf{E}$ and $\mathbf{F}$ : Immunofluorescence staining for $\beta$-catenin and Ki-67 (red), respectively. Nuclei were labeled with DAPI (blue). $n=4$ (A and $\mathbf{B}) ; n=3(\mathbf{C}-\mathbf{F}) .{ }^{*} P<0.05,{ }^{*} P<0.01$, and ${ }^{* *} P<0.001$. Scale bars $=5 \mu \mathrm{m}(\mathbf{E}$ and $\mathbf{F})$. GAPDH, glyceraldehyde-3-phosphate dehydrogenase; TCF4, transcription factor 4.

\section{Statistical Analysis}

Data for each group are expressed as the means $\pm \mathrm{SD}$. Statistical analyses were performed using SPSS version 17.0 (SPSS, Inc., Chicago, IL). Data for two groups were compared using an unpaired $t$-test, and one-way analysis of variance was used for multiple comparisons. Differences with $P<0.05$ were considered statistically significant.

\section{Results}

Differences in the Insulin Content and IR Expression in Corneal Tissue Between Diabetic and Normal Mice

Western blot analysis and immunofluorescence showed that the IR was widely distributed, but its levels of expression were lower in the intact corneal epithelial cells of the diabetic mice than in those of the normal mice (Figure 1, A, B, and D). Using enzyme-linked immunosorbent assay, it was found that the insulin content was significantly lower in the intact corneal epithelial cells of the diabetic mice than in those of the normal mice (Figure 1C).

Local Insulin Application Promotes Corneal Epithelial Wound Healing and Enhances IRS1 Phosphorylation and the Expression of Wnt/ $\beta$-Catenin Signaling Molecules in Corneal Epithelial Cells

Corneal fluorescein staining was observed at different time points after corneal epithelial scraping in the control and diabetic groups, as well in the diabetic group that received insulin eye drops. Corneal epithelial curettage at 48 and 72 hours after scraping showed that the percentage of the corneal epithelial defect area was significantly higher in the diabetic mice than in the normal and insulin-treated mice (Figure 2, A 


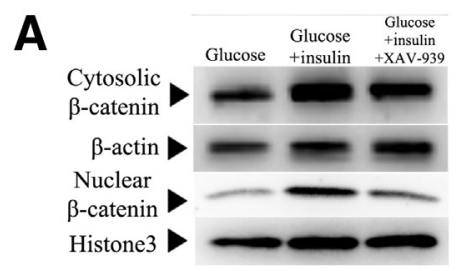

C

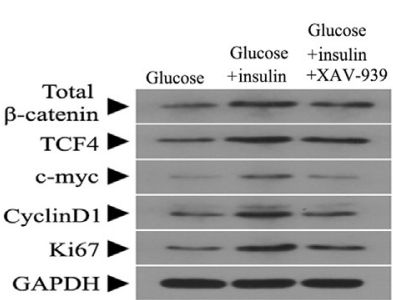

E

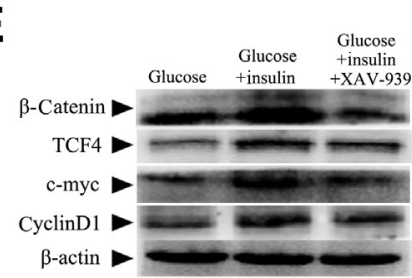

G
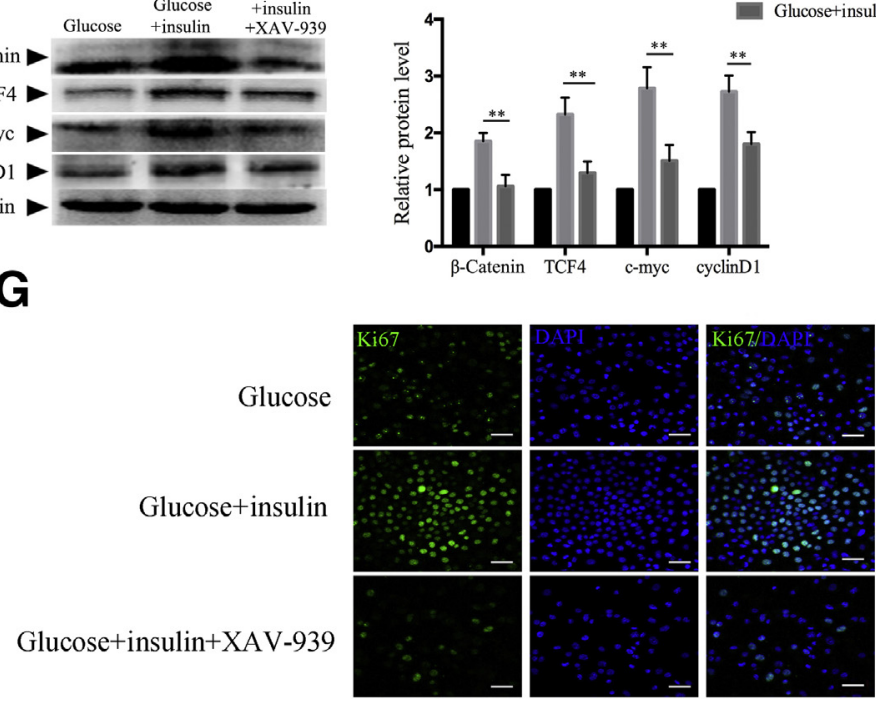
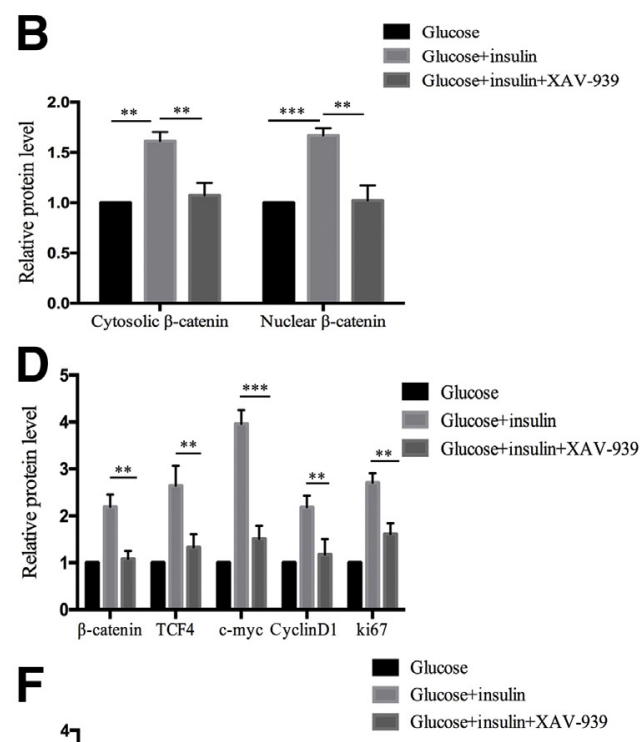

Glucose+insulin+XAV-939

and B), suggesting that corneal epithelial healing was delayed in the diabetic mice and that insulin improved healing.

The corneal epithelium was examined by Western blotting 48 hours after corneal epithelial scraping. It was found that insulin treatment significantly increased the levels of phosphorylated IRS1, the expression of the $\mathrm{Wnt} / \beta$-catenin signaling pathway-related factors $\beta$-catenin, TCF4, c-Myc, and cyclin D1, and that of Ki-67 in the diabetic mice (Figure 2, C and D). Furthermore, immunofluorescence analysis of the spatial distribution of $\beta$-catenin and Ki-67 in corneal samples showed that $\beta$-catenin accumulated and Ki$67-$ positive staining of the corneal epithelium increased in the insulin treatment group (Figure 2, E and F).

In vitro, the level of phosphorylated IRS1 and the expression of $\mathrm{Wnt} / \beta$-catenin signaling pathway-related proteins (nuclear and cytoplasmic $\beta$-catenin, TCF4, cMyc, and cyclin D1) and Ki-67 were higher in the insulintreated group than in the high-glucose group at 24 hours after injury (Figure 3, A-D). At the time when the wound was closed (72 hours), the levels of phosphorylated IRS1
Figure 5 Wnt/ $\beta$-catenin signaling antagonist attenuates the effect of insulin on TKE2 cells. A and B: Representative Western blots showing cytosolic and nuclear $\beta$-catenin levels in the glucose, glucose + insulin, and glucose + insulin + XAV-939 groups at 24 hours after injury in an in vitro scratch assay. The results show that the cytosolic and nuclear levels of $\beta$ catenin are significantly lower in the glucose and glucose + insulin + XAV-939 groups than in the glucose + insulin group. C: Representative Western blots showing the expression levels of Wnt pathway-related proteins and Ki-67 in the three groups. D: Statistical analysis shows that XAV-939 reduces the relative expression levels of the Wnt pathway-related proteins at 24 hours after injury in an in vitro scratch assay. E: Representative Western blots showing the Wnt pathway-related protein and Ki-67 expression levels in the three groups at 72 hours after injury in an in vitro scratch assay. F: Statistical analysis of the relative expression levels shows that insulin still attenuates the inhibition of the Wnt pathway-related proteins. G: Immunofluorescence staining for Ki67 (green). Nuclei were labeled with DAPI (blue). $n=3(\mathbf{A}-\mathbf{G}) .{ }^{* *} P<0.01,{ }^{* * *} P<0.001$. Scale bars $=50 \mu \mathrm{m}(\mathbf{G})$. GAPDH, glyceraldehyde-3phosphate dehydrogenase; TCF4, transcription factor 4. and Wnt pathway-related proteins were still higher in the insulin-treated group (Figure 3, E and F). Immunofluorescence results also showed that the Ki-67-positive staining increased in the insulin-treated group (Figure 3G).

\section{Inhibition of the Wnt/ $\beta$-Catenin Signaling Pathway Attenuates the Effect of Insulin on Diabetic Corneal Epithelial Repair}

Next, the Wnt pathway was blocked, and the effects of insulin on the healing of the corneal epithelium were observed using fluorescein sodium staining 48 hours after scraping. The corneal epithelial defect area was significantly larger in the inhibitor-treated group than in the insulin-treated group (Figure 4, A and B). In addition, the expression levels of $\beta$ catenin, TCF4, c-Myc, cyclin D1, and Ki-67 were significantly lower in the corneal epithelium of the XAV939-treated group than in that of the insulin-treated group (Figure 4, C and D). The distribution of $\beta$-catenin and Ki-67 was evaluated by immunohistochemistry. In the inhibitor 


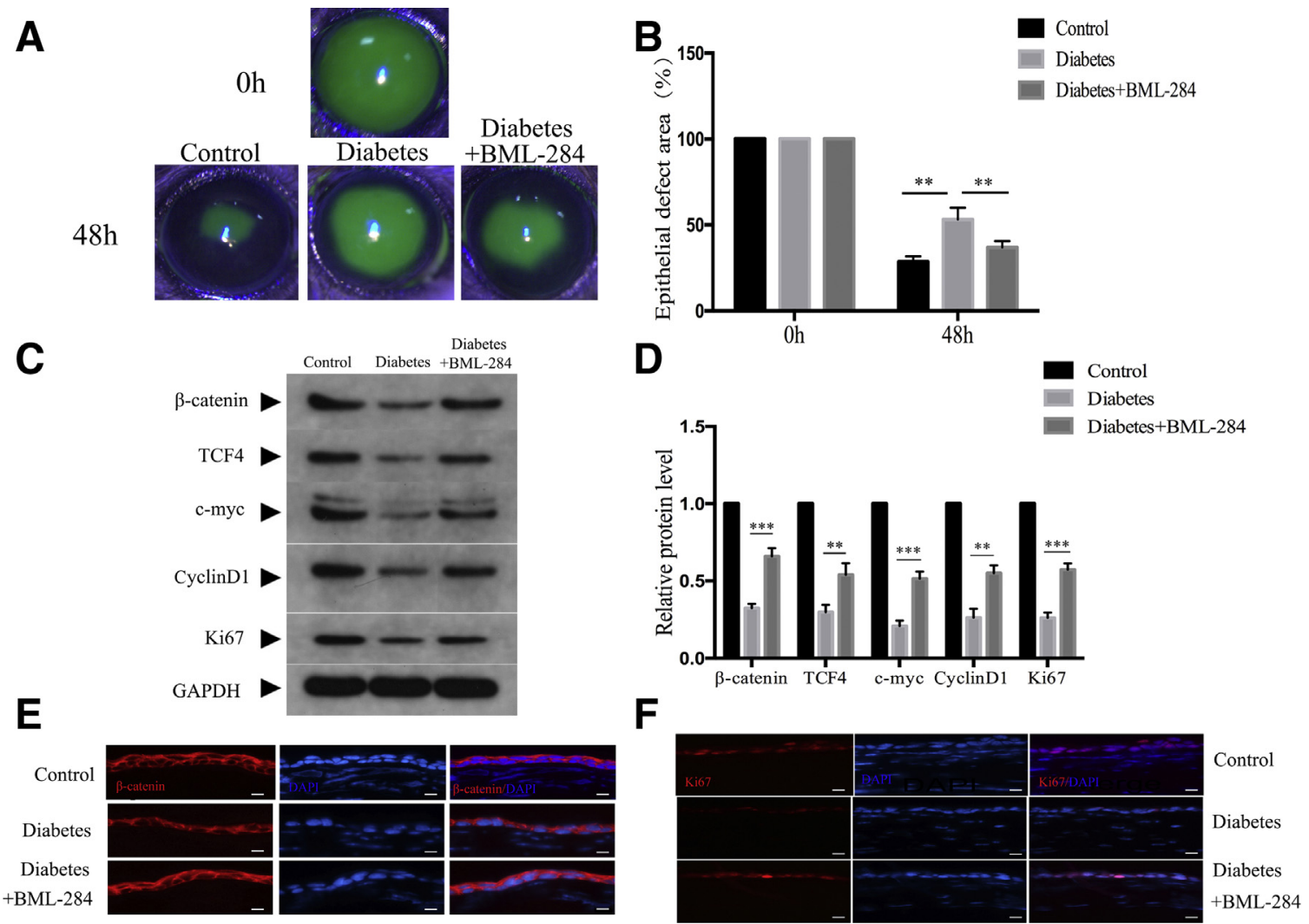

Figure 6 Activation of the Wnt/ $\beta$-catenin signaling pathway promotes diabetic corneal epithelial healing. The Wnt/ $\beta$-catenin signaling activator BML-284 was administered via subconjunctival injection to mice. A: Repair of the corneal epithelium in mice, as assessed by fluorescein sodium staining. B: Statistical analysis of the percentages of the mouse corneal defect areas at the indicated time points. C: Representative Western blots showing the $\beta$-catenin, TCF4, CMyc, cyclin D1, and Ki-67 expression levels in the corneal epithelium. D: Statistical analysis of the relative protein expression levels in the corneal epithelium. The results indicate that BML-284 increases the levels of the Wnt signaling pathway-related proteins and shows a similar effect with that of insulin. $\mathbf{E}$ and $\mathbf{F}$ : Immunofluorescence staining for $\beta$-catenin (red; E) and Ki-67 (red; F) in the cornea. Nuclei were labeled with DAPI (blue). $n=4(\mathbf{A}$ and $\mathbf{B}) ; n=3(\mathbf{C}-\mathbf{F})$. ${ }^{* *} P<0.01,{ }^{* * *} P<0.001$. Scale bars $=5 \mu \mathrm{m}$ (E and $\left.\mathbf{F}\right)$. GAPDH, glyceraldehyde-3-phosphate dehydrogenase; TCF4, transcription factor 4 .

group, the accumulation of $\beta$-catenin decreased, as did the positive staining for Ki-67 (Figure 4, E and F).

In in vitro experiments, significantly lower levels of $\beta$ catenin (nuclear and cytoplasmic), TCF4, c-Myc, cyclin D1, and $\mathrm{Ki}-67$ were found in the XAV-939-treated group than in the insulin-treated group at 24 hours after injury (Figure 5, A-D). The levels of these Wnt pathway-related proteins were still lower at 72 hours after injury (Figure 5, $\mathrm{E}$ and $\mathrm{F})$. Also, the frequency of $\mathrm{Ki}-67-$ positive staining was lower in the inhibitor-treated group than in the insulintreated group (Figure 5G). These results indicated that inhibition of the Wnt/ $/$-catenin signaling pathway weakened the positive effects of insulin on TKE2 cells.

\section{Activation of the Wnt/ $\beta$-Catenin Signaling Pathway Promotes Diabetic Corneal Epithelial Healing}

To further study the role of the $\mathrm{Wnt} / \beta$-catenin signaling pathway in the healing of the corneal epithelium, subconjunctival injection of the pathway activator BML-284 was administered to diabetic mice. Compared with that in the untreated diabetic mice, the corneal epithelial healing rate was significantly accelerated in the BML-284-treated group (Figure 6, A and B). BML-284 treatment also significantly increased the levels of $\beta$-catenin, TCF4, cMyc, cyclin D1, and Ki-67 compared with those in the untreated diabetic mice (Figure 6, C and D). Immunofluorescence also showed that the accumulation of the $\mathrm{Wnt} / \beta$ catenin signaling pathway-related proteins $\beta$-catenin and $\mathrm{Ki}$ 67 was higher in the BML-284-treated group than in the untreated diabetic mice (Figure 6, E and F).

Using in vitro Western blotting and immunofluorescence staining, it was found that the BML-284-treated group had significantly higher levels of expression of $\beta$-catenin (nuclear and cytoplasmic), TCF4, c-Myc, cyclin D1, and Ki-67 than the high-glucose group at 24 and 72 hours after injury (Figure 7, A-F). The frequency of Ki-67-positive staining was higher in the BML-284-treated group than in the glucose-alone group (Figure $7 \mathrm{G}$ ).

Local Application of Insulin and Activation of Wnt/ $\beta$ Catenin Signaling Promote Corneal Nerve Repair in Diabetes

To observe the effects of insulin and activation or inhibition of $\mathrm{Wnt} / \beta$-catenin signaling on corneal nerve regeneration 
A

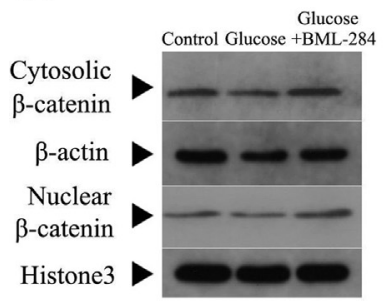

C

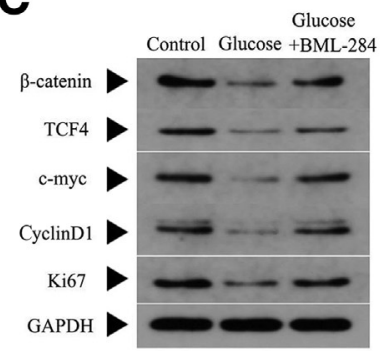

E

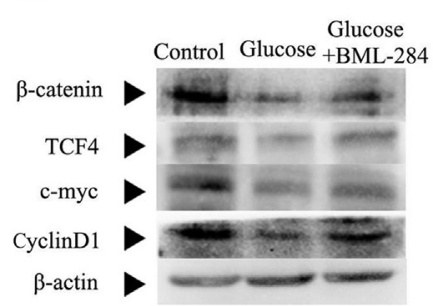

G

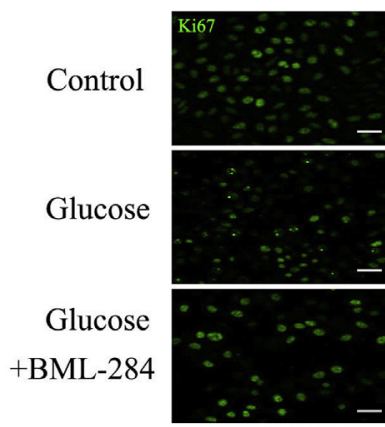

B
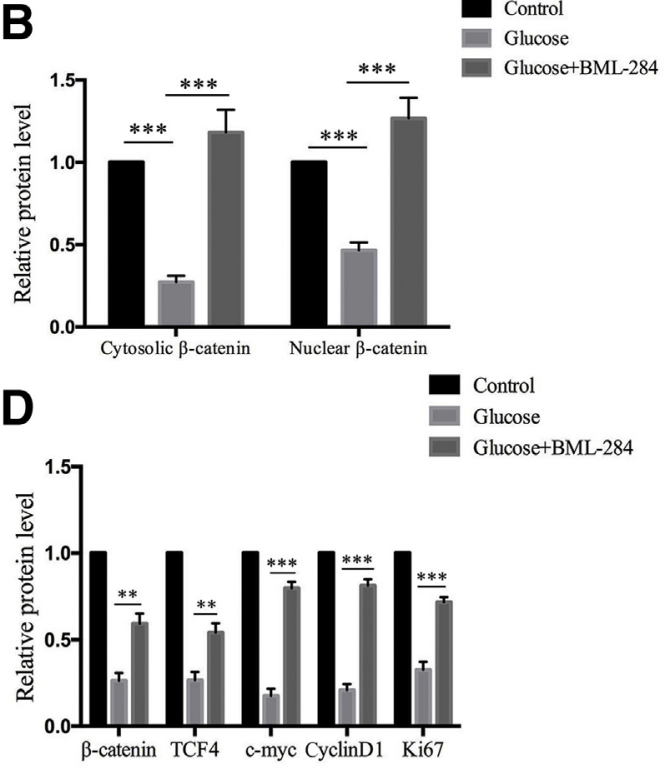

$\mathbf{F}$
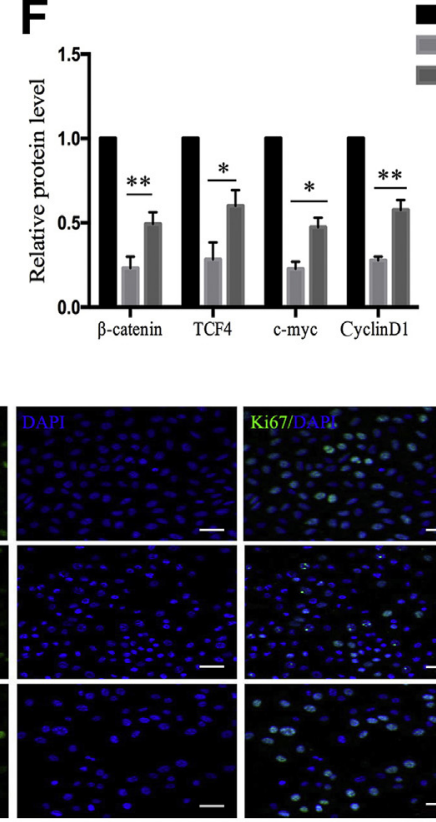

Control Glucose Glucose+BML-284

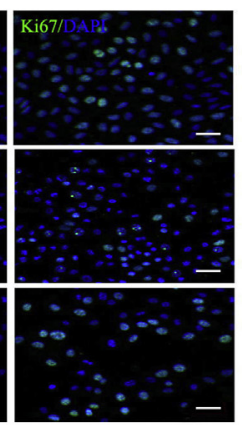

Figure 7 Activation of the $W n t / \beta$-catenin signaling pathway plays a similar role with that of insulin under high-glucose conditions. A and B: Representative Western blots showing the cytosolic and nuclear $\beta$-catenin levels in the control, glucose, and glucose + BML-284 groups at 24 hours after injury in an in vitro scratch assay. The results indicate that the cytosolic and nuclear $\beta$ catenin levels are significantly higher in the glucose + BML-284 group than in the glucose group. C: Representative Western blots showing the expression levels of Wnt pathway-related proteins and Ki-67 in the three groups. D: Statistical analysis shows that BML-284 increases the relative expression levels of the Wnt pathway-related proteins at 24 hours after injury in an in vitro scratch assay. E: Representative Western blots showing the expression levels of Wnt pathway-related proteins and $\mathrm{Ki}-67$ in the three groups at 72 hours after injury in an in vitro scratch assay. F: Statistical analysis shows that the relative expression levels of the Wnt pathway-related proteins are still higher in the BML-284 group than in the glucose group. G: Immunofluorescence staining for Ki-67 (green). Nuclei were labeled with DAPI (blue). $n=3$ (A-G). ${ }^{*} P<0.05,{ }^{*} P<0.01$, and $* * * P<0.001$. Scale bars $=50 \mu \mathrm{m}$ (G). GAPDH, glyceraldehyde-3-phosphate dehydrogenase; TCF4, transcription factor 4 . after epithelial scraping, insulin eye drops were applied to the corneal epithelium of the diabetic mice for 1 week after the procedure and subconjunctival injections of the Wnt/ $\beta$ catenin signaling pathway activator BML-284 and inhibitor XAV-939 were administered. The results of corneal nerve regeneration revealed that BML-284 and insulin treatment significantly increased the subbasal nerve fiber density in the diabetic mice, whereas the opposite results were obtained in the untreated diabetic and insulin + XAV939-treated groups (Figure 8, A-F).

The corneal nerve sensitivity was significantly lower in the diabetic and XAV-939-treated mice than in the normal and insulin- and BML-284-treated mice (Figure 8G).
In vitro cultured trigeminal ganglion cells have the characteristics of neurite outgrowth. The neuroprotective effects of insulin and Wnt signaling are reflected by the axonal growth state. Trigeminal ganglion cells in the normal, mannitol, high-glucose, high-glucose + insulin, high-glucose + insulin + XAV-939, and highglucose + BML-284 groups were assessed by immunofluorescence. The results showed that the axonal length in the high-glucose group increased more slowly and to a lesser extent than that in the high-glucose + insulin group (Figure 9, A-D and G). However, the positive effect of insulin was attenuated by the Wnt pathway inhibitor (Figure 9, D, E, and G). Meanwhile, the activator of the Wnt 

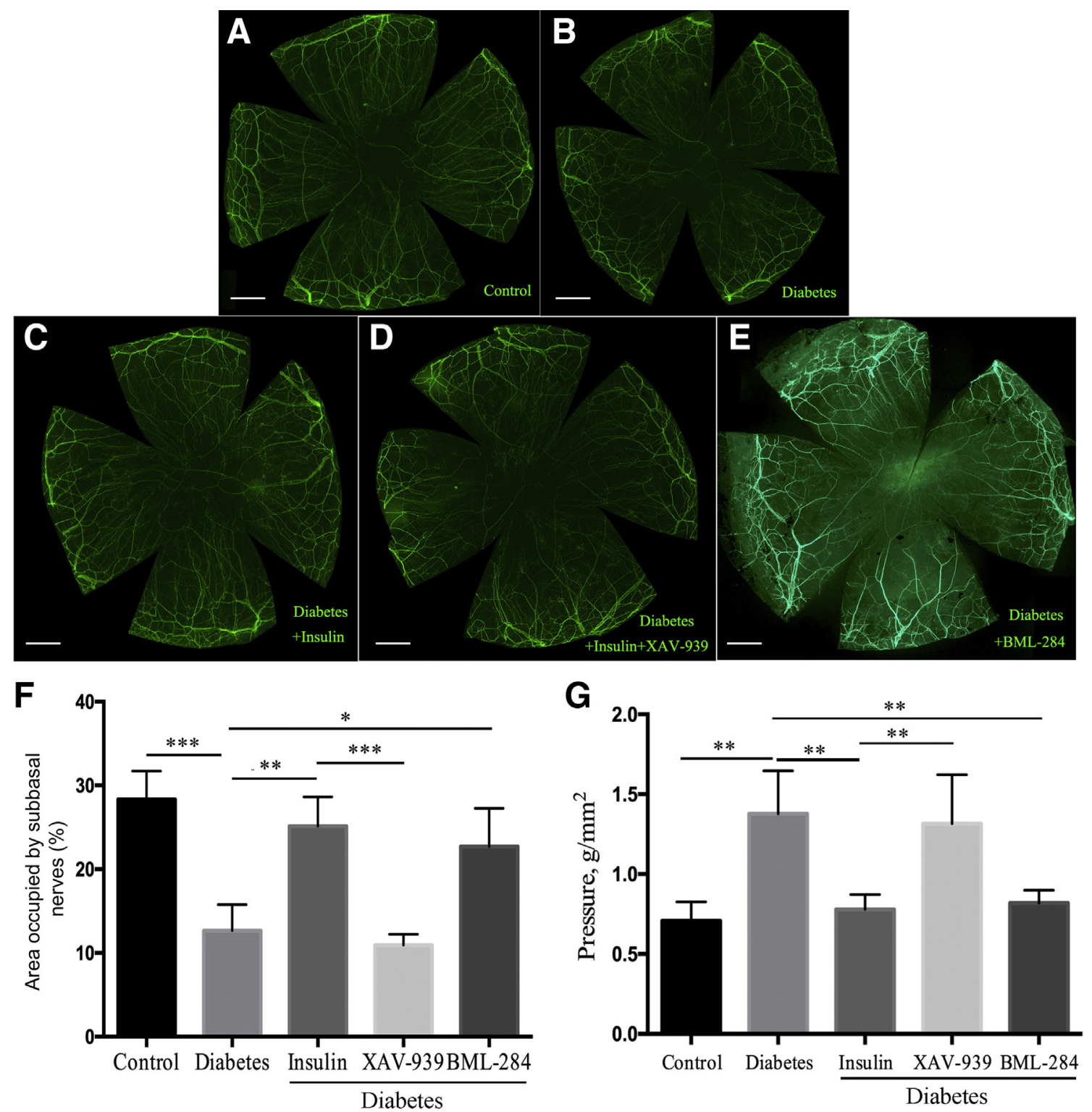

Figure 8 The insulin and Wnt/ $\beta$-catenin signaling pathways work together to promote corneal nerve repair in diabetic mice. Local application of insulin was continued for 1 week after epithelial scraping in diabetic mice. A-E: Representative images of the whole zone of subbasal nerves in the corneas from the control, diabetes, diabetes + insulin, diabetes + insulin + XAV-939, and diabetes + BML-284 groups ( $\beta$ III-tubulin, green). F: Statistical analysis of the nerve density involved in the corneal subbasal nerve regeneration in the whole corneas. The data show that the nerve density is significantly higher in the insulin group than in the diabetic group. XAV-939 treatment significantly reduces the effect of insulin. BML-284 shows a similar effect with that of insulin, with a significantly higher percentage of the nerve repair density than that in the diabetic group. G: Statistical analysis of the corneal nerve sensitivity in the three experimental groups. The measured fiber lengths were converted to the actual pressure values and then compared using statistical analysis. The higher the actual pressure value in the figure, the lower the corneal nerve sensitivity. $n=5(\mathbf{A}-\mathbf{F}) ; n=4(\mathbf{G})$. ${ }^{*} P<0.05,{ }^{* *} P<0.01$, and ${ }^{* * *} P<0.001$. Scale bars $=500 \mu \mathrm{m}(\mathbf{A}-\mathbf{E})$.

pathway significantly promoted the growth of nerve fibers in the high-glucose group (Figure 9, C, F, and G).

Simultaneously, the Wnt-downstream signal factors were detected in the TGs of the above six groups using real-time quantitative PCR. The results showed that insulin and BML284 could increase the mRNA expression levels of Wnt related factors [ $\beta$-catenin (alias Ctnnb1), c-Myc (alias Myc), cyclin D1 (Ccnd1), and Tcf4). In contrast, XAV-939 significantly decreased the expression of the abovementioned factors (Figure 9H).

\section{Discussion}

Insulin is a crucial hormone for the maintenance of regular physiological activity, including normal glucose metabolism. Its role in promoting tissue and wound healing has become a focus of research, given that the treatment with insulin is practical and cost effective. ${ }^{36,41,42}$ Studies have shown that the application of insulin to wounded skin tissue can directly activate the downstream phosphatidylinositol 

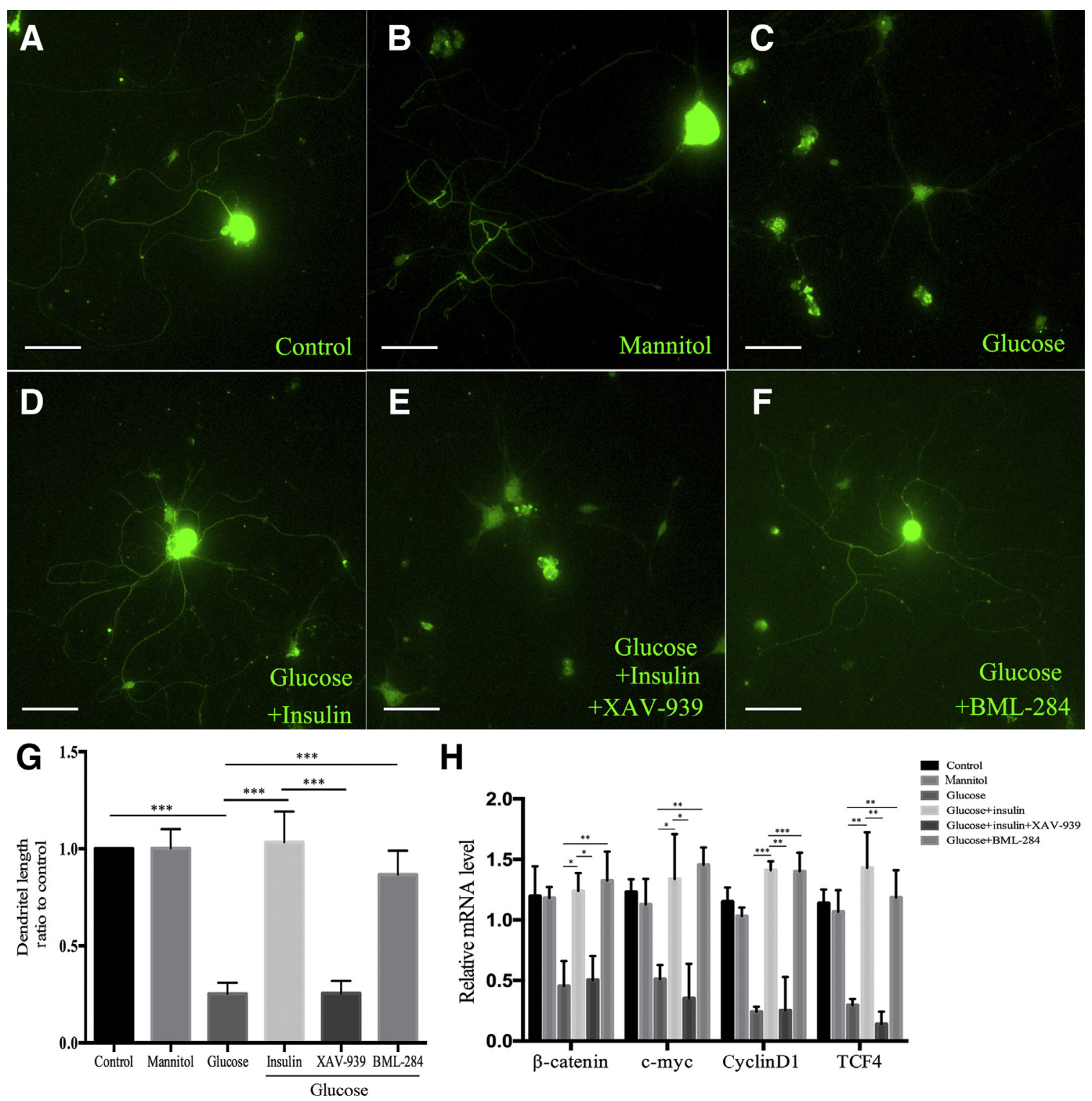

Figure 9 Insulin and the activator of the Wnt/ $\beta$-catenin signaling pathway promote the growth of trigeminal ganglion cells. A-F: Immunofluorescence staining of ex vivo cultured mouse trigeminal ganglion cells from the control, mannitol, glucose, glucose + insulin, glucose + insulin + XAV-939, and glucose + BML-284 groups ( $\beta$ III tubulin, green). G: Statistical analysis of the relative axonal lengths of ex vivo cultured mouse trigeminal ganglion cells from each treatment group. The results show that insulin and BML-284 promote the axonal growth of trigeminal ganglion cells in a high-glucose environment, whereas XAV-939 weakens the effect of insulin. H: Relative mRNA expression levels of $\beta$-catenin (alias Ctnnb1), c-myc (alias Myc), cyclin D1 (Ccnd1), and TCF4 (alias Tcf4) were statistically analyzed in ganglion cells. The results show that insulin and BML-284 activate Wnt signaling in trigeminal ganglion cells in a high-glucose environment. $n=3(\mathbf{A}-\mathbf{H}) .{ }^{*} P<0.05,{ }^{*} P<0.01$, and ${ }^{* *} P<0.001$. Scale bars $=10 \mu \mathrm{m}(\mathbf{A}-\mathbf{F})$.

3-kinase/AKT and phosphorylated extracellular signalregulated kinase pathways, thereby promoting wound healing. ${ }^{43}$ Clinical studies have also shown that topical application of insulin can promote the healing of diabetic foot and skin ulcers and improve wound tissue morphology. ${ }^{44,45}$ The primary mechanism of insulin action involves the activation of insulin signaling, phosphorylation of IRS1, and initiation of closely related downstream signaling pathways. ${ }^{43}$ In the corneas of mice, the IR is widely expressed in epithelial cells (Figure 1). This finding reflects the physiological basis for the direct action of insulin on corneal tissue. Zagon et $\mathrm{al}^{33}$ observed that the topical application of insulin promoted the healing of diabetic corneal epithelial injury. Although insulin promotes neuronal cell differentiation and maturation in vitro, its effect on the diabetic corneal nerve has not been elucidated. . $^{4,45}$

The cornea, as the tissue with the highest abundance of nerve terminals, could potentially greatly benefit from insulin treatment to enhance the repair of corneal nerves. ${ }^{34}$ To gain a more comprehensive understanding of the effects of insulin for the treatment of diabetic keratopathy, mouse 


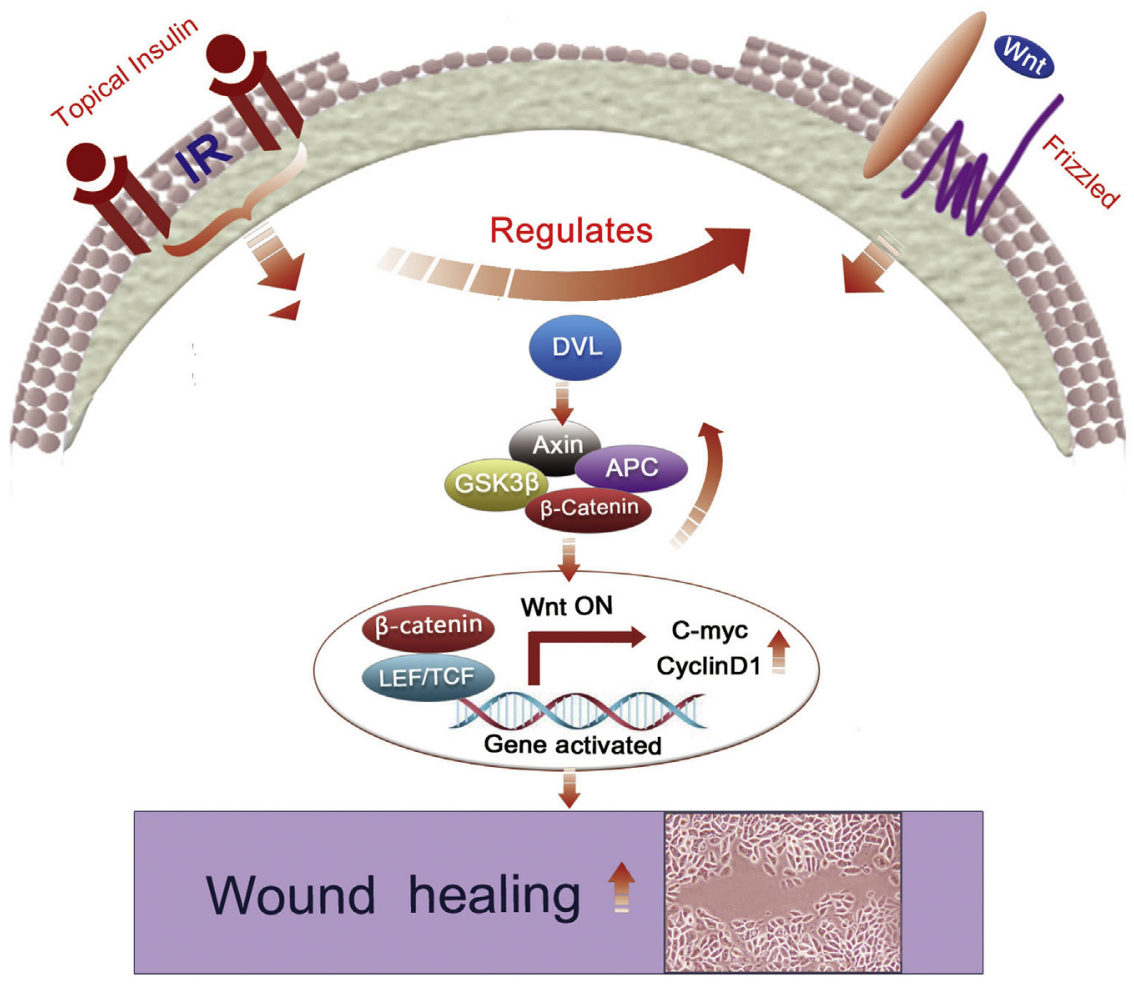

Figure 10 Schematic illustration of corneal wound healing and nerve repair mediated by the interaction between the insulin and Wnt signaling pathways. Binding of locally applied insulin to the insulin receptor (IR) activates the insulin signaling pathway and promotes the accumulation of $\beta$ catenin in the cytoplasm; subsequently, $\beta$-catenin enters the nucleus to activate the Wnt signaling pathway, promote the transcription and translation of related genes [c-Myc (alias Myc) cyclin D1 (Ccnd1), and Tcf4], and facilitate the repair of corneal epithelium and nerve injury. APC, adenomatous polyposis coli; DVL, dishevelled; GSK3, glycogen synthase kinase-3; LEF, lymphoid enhancer-binding factor; TCF, transcription factor.

corneas were observed after topical application of insulin and showed that insulin improved corneal nerve repair and sensitivity in diabetic mice. More important, no obvious side effects or adverse effects were observed on the blood glucose levels, intraocular pressure, or corneal epithelium after long-term application of insulin (Supplemental Figure S1), which was consistent with the data of previous studies. $^{34,46,47}$

The Wnt/ $/$-catenin signaling pathway is essential for the healing process of wounded tissue. ${ }^{14-23}$ In our preliminary study, different levels of expression of $\mathrm{Wnt} / \beta$-catenin signaling pathway-related molecules at different time points after corneal epithelial injury were demonstrated (Supplemental Figure S2). There also was an abnormal decrease in corneal injury healing in diabetic mice (Supplemental Figure S3). Many studies have confirmed the interaction between the insulin and Wnt signaling pathways. ${ }^{48-50}$ In this study, we investigated, for the first time, whether local application of insulin could promote the healing of the corneal epithelium and nerve repair in diabetic mice via the activation of the $\mathrm{Wnt} / \beta$-catenin signaling pathway. After treatment with insulin, the expression of $\beta$ catenin, the key factor in the $\mathrm{Wnt} / \beta$-catenin signaling pathway, increased in corneal epithelial tissue and TKE2 cells. The downstream factors in the pathway, TCF4, cMyc, and cyclin D1, were also up-regulated, and the expression of Ki-67 increased. The activation of this pathway alone could markedly enhance the healing speed of the corneal epithelium. These results suggest that local application of insulin stimulates the accumulation of $\beta$-catenin in the cell, activates the $\mathrm{Wnt} / \beta$-catenin signaling pathway, and ultimately promotes cell proliferation. To further explore the relationship between the insulin and Wnt/ $\beta$-catenin signaling pathways in corneal epithelial wound healing and nerve repair in diabetic mice, a $\mathrm{Wnt} / \beta$ catenin inhibitor was used to block the pathway and showed that the inhibitor significantly suppressed the insulininduced wound healing. Moreover, the expression of a limbal stem cell marker $(\Delta \mathrm{Np} 63)$ also increased under the influence of insulin and a Wnt pathway activator (Supplemental Figure S4). It is clear that the Wnt/B-catenin signaling pathway itself plays a key role in the normal physiological activity of cells, and because of its complex relationships, blocking of the Wnt signaling pathway will affect other pathways. The broad effects of the pharmacologic agents used may be a limitation of this study.

In the clinic, most patients with diabetes have type 2 diabetes mellitus; therefore, a preliminary study of type 2 diabetic mice was conducted. The data showed that the topical application of insulin could also promote epithelial repair after corneal injury in type 2 diabetic mice (Supplemental Figure S5A), which may be due to a particular mechanism of insulin resistance (Supplemental Figure S5B) in the corneas of these mice. We will perform further research to more clearly define the mechanism of insulin action.

In conclusion, our findings revealed that insulin, via Wnt signaling, contributes to diabetic corneal epithelial wound healing and nerve injury recovery (Figure 10), and is, 
therefore, a potential protective factor for diabetic corneal epithelial wounds and nerve injury.

\section{Author Contributions}

S.Y. designed and conducted the experiments, analyzed the data, and prepared the manuscript; Y.Y.Z., H.Z.Z., J.D., C.X.W., N.W.L., and L.Z. conducted the experiments; J.Q.Z. assisted with the study design and reviewed the manuscript; all authors have read and approved the final version of the manuscript. X.L.X. and L.L.Y. are the guarantors of this work; they assisted with the study design and reviewed the manuscript.

\section{Supplemental Data}

Supplemental material for this article can be found at http://doi.org/10.1016/j.ajpath.2020.08.006.

\section{References}

1. Mahoney JE, Gray SL, Carnes M: Prevention and treatment of the complications of diabetes mellitus. N Engl J Med 1995, 333:802

2. Herse PR: A review of manifestations of diabetes mellitus in the anterior eye and cornea. Am J Optom Physiol Opt 1988, 65:224-230

3. Misra SL, Braatvedt GD, Patel DV: Impact of diabetes mellitus on the ocular surface: a review. Clin Exp Ophthalmol 2016, 44:278-288

4. Haddad NM, Sun JK, Abujaber S, Schlossman DK, Silva PS: Cataract surgery and its complications in diabetic patients. Semin Ophthalmol 2014, 29:329-337

5. Calvo-Maroto AM, Perez-Cambrodí RJ, Albarán-Diego C, Pons A, Cerviño A: Optical quality of the diabetic eye: a review. Eye (Lond) 2014, 28:1271-1280

6. Stitt AW, Curtis TM, Chen M, Medina RJ, McKay GJ, Jenkins A, Gardiner TA, Lyons TJ, Hammes HP, Simó R, Lois N: The progress in understanding and treatment of diabetic retinopathy. Prog Retin Eye Res 2015, 51:156-186

7. Mariotti C, Dahan E, Nicolai M, Levitz L, Bouee S: Long-term outcomes and risk factors for failure with the EX-press glaucoma drainage device. Eye (Lond) 2014, 28:1-8

8. Wang Y, Zhao X, Wu X, Dai Y, Chen P, Xie L: MicroRNA-182 mediates Sirt1-induced diabetic corneal nerve regeneration. Diabetes 2016, 65:2020-2031

9. Yang L, Di G, Qi X, Qu M, Wang Y, Duan H, Danielson P, Xie L, Zhou Q: Substance P promotes diabetic corneal epithelial wound healing through molecular mechanisms mediated via the neurokinin-1 receptor. Diabetes 2014, 63:4262-4274

10. Zhang Y, Gao N, Wu L, Lee P, Me R, Dai C, Xie L, Yu F: Role of VIP and sonic hedgehog signaling pathways in mediating epithelial wound healing, sensory nerve regeneration, and their defects in diabetic corneas. Diabetes 2020, 69:1549-1561

11. Gao J, Wang Y, Zhao X, Chen P, Xie L: MicroRNA-204$5 p-$ mediated regulation of SIRT1 contributes to the delay of epithelial cell cycle traversal in diabetic corneas: restoration of cell cycle in diabetic corneal epithelium. Invest Ophthalmol Vis Sci 2015, 56:1493-1504

12. Guo C, Li M, Qi X, Lin G, Cui F, Li F, Wu X: Intranasal delivery of nanomicelle curcumin promotes corneal epithelial wound healing in streptozotocin-induced diabetic mice. Sci Rep 2016, 6:29753

13. Di G, Zhao X, Qi X, Zhang S, Feng L, Shi W, Zhou Q: VEGF-B promotes recovery of corneal innervations and trophic functions in diabetic mice. Sci Rep 2017, 7:40582
14. Rognoni E, Gomez C, Pisco AO, Rawlins EL, Simons BD, Watt FM, Driskell RR: Inhibition of $\beta$-catenin signalling in dermal fibroblasts enhances hair follicle regeneration during wound healing. Development 2016, 143:2522-2535

15. Zhang J, Li S, Wu Y: Recovery of spinal cord injury following electroacupuncture in rats through enhancement of Wnt/ $\beta$-catenin signaling. Mol Med Rep 2017, 16:2185-2190

16. Zhang DL, Gu LJ, Liu L, Wang CY, Sun BS, Li Z, Sung CK: Effect of Wnt signaling pathway on wound healing. Biochem Biophys Res Commun 2009, 378:149-151

17. Amini-Nik S, Cambridge E, Yu W, Guo A, Whetstone H, Nadesan P, Poon R, Hinz B, Alman BA: $\beta$-Catenin-regulated myeloid cell adhesion and migration determine wound healing. J Clin Invest 2014, 124:2599-2610

18. Houschyar KS, Momeni A, Pyles MN, Maan ZN, Whittam AJ, Siemers F: Wnt signaling during cutaneous wound healing. Organogenesis 2015, 11:95-104

19. Nakatsu MN, Ding Z, Ng MY, Truong TT, Yu F, Deng SX: Wnt/Bcatenin signaling regulates proliferation of human cornea epithelial stem/progenitor cells. Invest Ophthalmol Vis Sci 2011, 52: 4734-4741

20. Lu R, Bian F, Zhang X, Qi H, Chuang EY, Pflugfelder SC, Li DQ: The $\beta$-catenin/Tcf4/survivin signaling maintains a less differentiated phenotype and high proliferative capacity of human corneal epithelial progenitor cells. Int J Biochem Cell Biol 2011, 43:751-759

21. Lyu J, Joo CK: Wnt-7a up-regulates matrix metalloproteinase-12 expression and promotes cell proliferation in corneal epithelial cells during wound healing. J Biol Chem 2005, 280:21653-21660

22. Lyu J, Joo CK: Expression of Wnt and MMP in epithelial cells during corneal wound healing. Cornea 2006, 25(10 Suppl):S24-S28

23. Ouyang H, Xue Y, Lin Y, Zhang X, Xi L, Patel S, Cai H, Luo J, Zhang M, Zhang M, Yang Y, Li G, Li H, Jiang W, Yeh E, Lin J, Pei M, Zhu J, Cao G, Zhang L, Yu B, Chen S, Fu XD, Liu Y, Zhang K: WNT7A and PAX6 define corneal epithelium homeostasis and pathogenesis. Nature 2014, 511:358-361

24. Fujimura N: WNT/B-catenin signaling in vertebrate eye development Front Cell Dev Biol 2016, 4:138

25. Clevers H, Nusse R: Wnt/ $\beta$-catenin signaling and disease. Cell 2012 , 149:1192-1205

26. Guo X, Day TF, Jiang X, Garrett-Beal L, Topol L, Yang Y: Wnt/ßcatenin signaling is sufficient and necessary for synovial joint formation. Genes Dev 2004, 18:2404-2417

27. De Iongh RU, Abud HE, Hime GR: WNT/Frizzled signaling in eye development and disease. Front Biosci 2006, 11:2442-2464

28. Holly ME, El-Hodiri HM: FoxO3 regulation of retinal progenitor cells in vertebrate eye development. DevBio 2008, 319:496

29. Pillion DJ, Bartlett JD, Meezan E, Yang M, Crain RJ, Grizzle WE: Systemic absorption of insulin delivered topically to the rat eye Invest Ophthalmol Vis Sci 1991, 32:3021-3027

30. Rocha EM, Cunha DA, Carneiro EM, Boschero AC, Saad MJ, Velloso LA: Identification of insulin in the tear film and insulin receptor and IGF-1 receptor on the human ocular surface. Invest Ophthalmol Vis Sci 2002, 43:963-967

31. Rocha EM, de M Lima MH, Carvalho CR, Saad MJ, Velloso LA: Characterization of the insulin-signaling pathway in lacrimal and salivary glands of rats. Curr Eye Res 2000, 21:833-842

32. Feldman ST, Gately D, Seely BL, Schonthal A, Feramisco JR Stimulation of DNA synthesis and c-fos expression in corneal endothelium by insulin or insulin-like growth factor-I. Invest Ophthalmol Vis Sci 1993, 34:2105-2111

33. Zagon IS, Klocek MS, Sassani JW, McLaughlin PJ: Use of topical insulin to normalize corneal epithelial healing in diabetes mellitus. Arch Ophthalmol 2007, 125:1082-1088

34. Chen DK, Frizzi KE, Guernsey LS, Ladt K, Mizisin AP, Calcutt NA: Repeated monitoring of corneal nerves by confocal microscopy as an index of peripheral neuropathy in type-1 diabetic rodents and the effects of topical insulin. J Peripher Nerv Syst 2013, 18:306-315 
35. Klocek MS, Sassani JW, McLaughlin PJ, Zagon IS: Naltrexone and insulin are independently effective but not additive in accelerating corneal epithelial healing in type I diabetic rats. Exp Eye Res 2009, 89:686-692

36. Bastion ML, Ling KP: Topical insulin for healing of diabetic epithelial defects? a retrospective review of corneal debridement during vitreoretinal surgery in Malaysian patients. Med J Malaysia 2013, 68:208-216

37. Yang S, He H, Ma QS, Zhang Y, Zhu Y, Wan X, Wang FW, Wang SS, Liu L, Li B: Experimental study of the protective effects of SYVN1 against diabetic retinopathy. Sci Rep 2015, 5:14036

38. Gao N, Yan C, Lee P, Sun H, Yu FS: Dendritic cell dysfunction and diabetic sensory neuropathy in the cornea. J Clin Invest 2016, 126 : 1998-2011

39. Kawakita T, Shimmura S, Hornia A, Higa K, Tseng SC: Stratified epithelial sheets engineered from a single adult murine corneal/limbal progenitor cell. J Cell Mol Med 2008, 12:1303-1316

40. Dai Y, Zhao X, Chen P, Yu Y, Wang Y, Xie L: Neuropeptide FF promotes recovery of corneal nerve injury associated with hyperglycemia. Invest Ophthalmol Vis Sci 2015, 56:7754-7765

41. Apikoglu-Rabus S, Izzettin FV, Turan P, Ercan F: Effect of topical insulin on cutaneous wound healing in rats with or without acute diabetes. Clin Exp Dermatol 2010, 35:180-185

42. Madibally SV, Solomon V, Mitchell RN, Van De Water L, Yarmush ML, Toner M: Influence of insulin therapy on burn wound healing in rats. J Surg Res 2003, 109:92-100

43. Lima MH, Caricilli AM, de Abreu LL, Araújo EP, Pelegrinelli FF, Thirone AC, Tsukumo DM, Pessoa AF, dos Santos MF, de Moraes MA, Carvalheira JB, Velloso LA, Saad MJ: Topical insulin accelerates wound healing in diabetes by enhancing the AKT and ERK pathways: a double-blind placebo-controlled clinical trial. PLOS One 2012, 7:e36974

44. Desai M1, Li T, Ross MG: Fetal hypothalamic neuroprogenitor cell culture: preferential differentiation paths induced by leptin and insulin. Endocrinology 2011, 152:3192-3201

45. Chirivella L, Kirstein M, Ferrón SR, Domingo-Muelas A, Durupt FC, Acosta-Umanzor C, Cano-Jaimez M, Pérez-Sánchez F, Barbacid M, Ortega S, Burks DJ, Fariñas I: Cyclin-dependent kinase 4 regulates adult neural stem cell proliferation and differentiation in response to insulin. Stem Cells 2017, 35:2403-2416

46. Bartlett JD1, Slusser TG, Turner-Henson A, Singh KP, Atchison JA Pillion DJ: Toxicity of insulin administered chronically to human eye in vivo. J Ocul Pharmacol 1994, 10:101-107

47. Bartlett JD, Turner-Henson A, Atchison JA, Woolley TW, Pillion DJ: Insulin administration to the eyes of normoglycemic human volunteers. J Ocul Pharmacol 1994, 10:683-690

48. Palsgaard J, Emanuelli B, Winnay JN, Sumara G, Karsenty G, Kahn CR: Cross-talk between insulin and Wnt signaling in preadipocytes: role of Wnt co-receptor low density lipoprotein receptorrelated protein-5 (LRP5). J Biol Chem 2012, 287:12016-12026

49. Geng Y, Ju Y, Ren F, Qiu Y, Tomita Y, Tomoeda M, Kishida M, Wang Y, Jin L, Su F, Wei C, Jia B, Li Y, Chang Z: Insulin receptor substrate $1 / 2(\mathrm{IRS} 1 / 2)$ regulates $\mathrm{Wnt} / \beta$-catenin signaling through blocking autophagic degradation of dishevelled2. J Biol Chem 2014, 289:11230-11241

50. Yi F, Sun J, Lim GE, Fantus IG, Brubaker PL, Jin T: Cross talk between the insulin and Wnt signaling pathways: evidence from intestinal endocrine L cells. Endocrinology 2008, 149:2341-2351 